\title{
Excitatory Nicotinic and Desensitizing Muscarinic (M2) Effects on C-Nociceptors in Isolated Rat Skin
}

\author{
Nadia Bernardini, ${ }^{1}$ Susanne K. Sauer, ${ }^{1}$ Rainer Haberberger, ${ }^{2}$ Michael J. M. Fischer, ${ }^{1}$ and Peter W. Reeh ${ }^{1}$ \\ 1/nstitut für Physiologie und Experimentelle Pathophysiologie, Erlangen-Universität, Universitätstraße 17, 91054 Erlangen, \\ Germany, and 2/nstitut für Anatomie und Zellbiologie, Justus-Liebig-Universität, Aulweg 123, 353885 Giessen, Germany
}

The actions of different cholinergic agonists and antagonists were investigated on nociceptive afferents using the rat skinsaphenous nerve preparation, in vitro. Nicotine was able to weakly excite $\mathrm{C}$-nociceptors and to induce a mild sensitization to heat stimulation (in $77 \%$ of tested fibers) in a dosedependent manner $\left(10^{-6}\right.$ to $\left.10^{-5} \mathrm{M}\right)$, but it caused no alteration in mechanical responsiveness tested with von Frey hairs. Muscarine did not induce a significant nociceptor excitation, but almost all fibers exhibited a marked desensitization to mechanical and heat stimuli in a dose-dependent manner (from $10^{-6}$ to $10^{-4} \mathrm{M}$ ). The muscarinic effects could be prevented by the general muscarinic antagonist scopolamine $\left(10^{-5} \mathrm{M}\right)$, by the M3 antagonist 1,1-dimethyl-4-diphenylacetoxypiperidium oxide $\left(10^{-6} \mathrm{M}\right)$ co-applied with the $\mathrm{M} 2$ antagonist gallamine $\left(10^{-5} \mathrm{M}\right)$, and by gallamine alone. As positive control we used the relatively $\mathrm{M} 2$-selective agonist arecaidine $\left(10^{-6}\right.$ to $\left.10^{-5} \mathrm{M}\right)$, obtaining a similar desensitizing effect as with muscarine. Finally, we performed an immunocytochemical study that demonstrated the presence of M2 but not M3 receptors in thin epidermal nerve fibers of the rat hairy skin. Altogether, these data demonstrate opposite effects of nicotinic and muscarinic receptor stimulation on cutaneous nociceptors. M2 receptormediated depression of nociceptive responsiveness may convey a therapeutic, i.e., analgesic or antinociceptive, potential.

Key words: acetylcholine; analgesia; cholinergic; mechanosensitivity; pain; sensitization
Acetylcholine (ACh) is the classical neurotransmitter activating nicotinic as well as muscarinic receptor subtypes. ACh is generally considered to be an algogenic agent because it has been shown to produce burning pain when applied to human skin (Keele and Armstrong, 1964; Rukwied and Heyer, 1999). Nonetheless, its role in physiological pain mechanisms has not been clearly understood. In fact, it is still unknown whether ACh appears in inflammatory exudates or under other painful conditions, but possible extraneuronal sources of $\mathrm{ACh}$ in the close vicinity of primary afferent terminals have meanwhile been identified. For example, in the corneal epithelial cells, high concentrations of ACh have been found that may be released after injury, and $\mathrm{ACh}$ has been shown to excite corneal nerve endings (Pesin and Candia, 1982; Tanellian, 1991). Regarding skin, it has been demonstrated that human keratinocytes are able to synthesize and secrete ACh. Here, ACh plays a role in regulating cell-cell attachment, but in addition, it may be released in larger amounts after cutaneous injury (Grando et al., 1993). Moreover, the ability of dorsal root ganglion (DRG) cells to synthesize ACh has been reported (Tata et al., 1994).

In the rat skin-nerve preparation and in the cornea, only unmyelinated $\mathrm{C}$-fiber endings were excited by ACh and its analog carbachol, respectively (Tanellian, 1991; Steen and Reeh, 1993). The major finding was that repeated carbachol treatment of polymodal nociceptors left almost all fibers with a marked and

\footnotetext{
Received Dec. 27, 2000; revised Feb. 20, 2001; accepted Feb. 26, 2001.

This work was supported by Deutsche Forschungsgemeinschaft, SFB 353-B12. N. Bernardini was supported by a post-graduate fellowship of the Universitá "La Sapienza," Roma, Italy. We thank I. Muller-Roth and U. Nesnidal for technical assistance. Dr. Gabor Pethoe provided technical advice.

Correspondence should be addressed to Nadia Bernardini, Institut für Physiologie und Experimentelle Pathophysiologie, Erlangen-Universität, Universitätstrasse 17, 91054 Erlangen, Germany. E-mail: bernardini@physiologie1.uni-erlangen.de. Copyright (C) 2001 Society for Neuroscience $0270-6474 / 01 / 213295-08 \$ 15.00 / 0$
}

sustained desensitization to mechanical stimulation (Steen and Reeh, 1993). If the physiological role of ACh lay in a capacity to desensitize nociceptors, this may convey a therapeutic, i.e., analgesic or antinociceptive, potential. A selective desensitizing effect of ACh would not be expected to be mediated by the nicotinic receptor-ion channel complex but by one of the five muscarinic receptor subtypes that connect to different second messenger pathways (Mei et al., 1989).

The presence of muscarinic AChRs (mAChRs) (Bauer et al., 1994; Wanke et al., 1994; Bernardini et al., 1998; Haberberger et al., 1999; Tata et al., 1999) as well as nicotinic AChRs (nAChRs) (Boyd et al., 1991; Zoli et al., 1995; Flores at al. 1996; Liu et al., 1998) in DRG cells is established. On the other hand, it is well documented that both nicotinic (Rao et al., 1996; Bannon et al., 1998; Traynor, 1998) and muscarinic receptors (Bartolini et al., 1992; Naguib and Yaksh, 1997; Ellis et al., 1999; Gomeza et al., 1999) are involved in the modulation of central nociception. Intrathecal administration of nicotinic agonists was shown to block heat nociception in the tail-flick assay (Rao et al., 1996; Bannon et al., 1998), and recent knock-out studies showed a crucial role of the muscarinic M2 and M4 receptor subtypes in mediating analgesic effects of oxotremorine administration as assessed in the hot-plate and the tail-flick tests (Ellis et al., 1999; Gomeza et al., 1999).

The present electrophysiological study sought to differentiate the effects of muscarinic and nicotinic agonists and antagonists on peripheral nociceptive terminals to clarify the physiological role of $\mathrm{ACh}$ in nociception.

\section{MATERIALS AND METHODS}

This study was performed using the in vitro rat skin-saphenous nerve preparation that has been described previously in detail (Reeh, 1986, 1988). 
A Nicotine Superfusion

Figure 1. Original recording from two $\mathrm{C}-\mathrm{MH}$ fibers of the saphenous nerve with receptive fields in isolated rat hairy skin, illustrating also the typical experimental protocol. Instantaneous discharge rates are plotted over a time scale of two different resolutions showing heat responses $\left(32-46^{\circ} \mathrm{C}\right.$ in $20 \mathrm{sec}$; gray columns) and responses to chemical stimuli (of $5 \mathrm{~min}$ duration); von Frey thresholds are indicated by open triangles. $A$ shows nicotine responses and a dose-dependently induced sensitization to heat. $B$ shows lack of muscarine-induced excitation and dose-dependent desensitization to heat and mechanical (von Frey) stimulation.

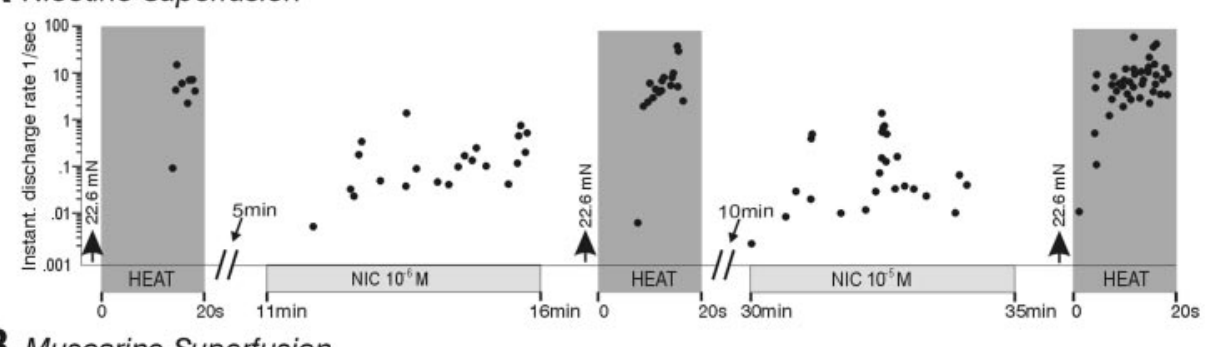

\section{B Muscarine Superfusion}

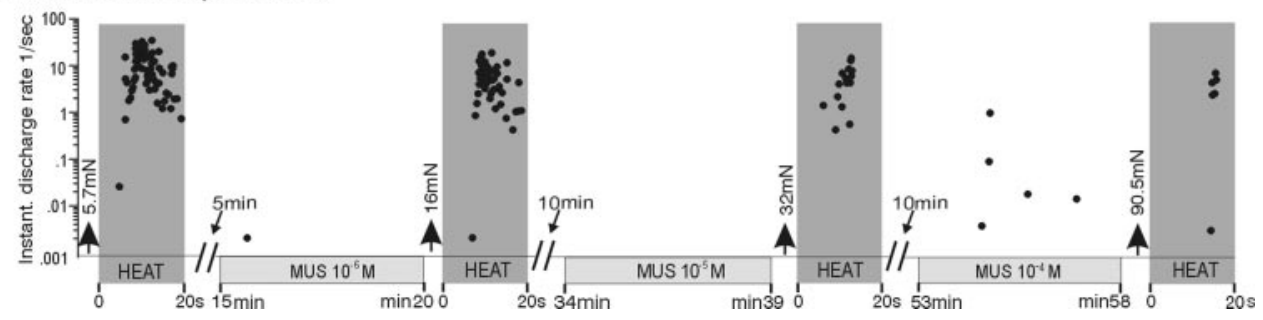

\section{General procedures}

The preparations were obtained from 62 home-bred male Wistar rats (200-380 gm) that were killed in a pure $\mathrm{CO}_{2}$ atmosphere. The saphenous nerve in continuity with the dorsal hindpaw skin was subcutaneously dissected and excised. The skin was pinned out, corium side up, in a Perspex chamber and kept under laminar superfusion $(16 \mathrm{ml} / \mathrm{min})$. The saphenous nerve was pulled through a hole into a second chamber where the aqueous solution [synthetic interstitial fluid (SIF); see below] was overlaid with paraffin oil; here the nerve was teased into smaller and smaller filaments until single-fiber unitary activity could be recorded via gold wire electrodes.

The skin was superfused with SIF containing (in mM): $108 \mathrm{NaCl}$, $3.48 \mathrm{KCl}, 3.5 \mathrm{MgSO}_{4}, 26 \mathrm{NaHCO}_{3}, 1.7 \mathrm{NaH}_{2} \mathrm{PO}_{4}, 1.5 \mathrm{CaCl}_{2}, 9.6$ sodium gluconate, 5.55 glucose, and 7.6 sucrose (Bretag, 1969), thermostatically controlled at $32^{\circ} \mathrm{C}$, and bubbled continuously with carbogen $\left(95 \% \mathrm{O}_{2}, 5 \% \mathrm{CO}_{2}\right)$.

\section{Characterization of $C$-fibers}

Receptive fields of $\mathrm{C}$-fibers were located by probing the corium side of the skin with a blunt glass rod. The nerve endings were electrically stimulated in their receptive fields via Teflon-insulated steel microelectrodes (impedance: 6-10 $\mathrm{M} \Omega$ ) to measure conduction velocity and establish the identity of mechanically and electrically evoked impulses using the "collision technique" (Iggo, 1958). The thresholds to mechanical stimulation were tested with a set of 18 von Frey hairs calibrated from 1 to $256 \mathrm{mN}$ in a geometric series $\left(x_{\mathrm{i}}=x_{\mathrm{i}-1} \times \sqrt{ } 2\right)$. Heat responsiveness was examined by focusing a halogen lamp through the translucent bottom of the skin chamber onto the epidermal side of the isolated receptive field. At the opposite corium side, the linearly increasing temperature (from 32 to $46^{\circ} \mathrm{C}$ in $20 \mathrm{sec}$, which corresponds to a rise from 32 to $52^{\circ} \mathrm{C}$ at the epidermal surface) (Reeh, 1986) was feedback controlled by a thermocouple. To isolate the receptive field, a metal ring was placed over the respective corium area, and the SIF content was evacuated. The temperature corresponding to the second spike of the heat response of a fiber was considered to be "heat threshold." For testing cold responsiveness, the ring was filled with cooled SIF at $\sim 4^{\circ} \mathrm{C}$.

\section{Chemical stimulation}

The metal rings to isolate receptive fields were also used for chemical stimulations. They had inner diameters of $6.6-9.6 \mathrm{~mm}$ and comprised volumes of $0.3-0.6 \mathrm{ml}$ that were perfused at $32^{\circ} \mathrm{C}$ with $2.25 \mathrm{ml} / \mathrm{min}$ to produce a turbulent flow. All solutions were bubbled continuously with carbogen.

Stock solutions $\left(10^{-3} \mathrm{M}\right)$ of all drugs used were kept frozen $\left(-20^{\circ} \mathrm{C}\right)$ and were freshly diluted in SIF for every experiment. The following agents were used: arecaidine-but-2ynyl ester (Tocris), gallamine-triethiodide (Sigma, St. Louis, MO), muscarine chloride (Sigma), nicotine (Sigma), scopolamine hydrobromide (Sigma) and 1,1 dimethyl-4diphenylacetoxypiperidium iodide (4-DAMP) (Sigma).

Control experiments. SIF was applied at the receptor field for $5 \mathrm{~min}$ before and after the mechanical and heat responsiveness were tested.
Agonist experiments. The cholinergic agonists nicotine, muscarine, or arecaidine at increasing $10^{-6}, 10^{-5}$, and $10^{-4}$ (only muscarine) $\mathrm{M}$ concentrations were superfused over the receptive fields for $5 \mathrm{~min}$ at 10 min intervals. After each drug administration the mechanical and heat thresholds were tested (Fig. 1A,B).

Antagonist experiments. The general muscarinic antagonist scopolamine and the specific M2 antagonist gallamine were used at $10^{-5} \mathrm{M}$ concentration, superfused over the receptive fields for $5 \mathrm{~min}$, and in combination with muscarine $10^{-5} \mathrm{M}$ for an additional $5 \mathrm{~min}$. Mechanical and heat thresholds were tested before and after drug application.

\section{Data analysis}

The single nerve fiber activity was recorded with a low-noise ACcoupled amplifier and monitored on a loudspeaker and an oscilloscope. The recordings were digitized and processed in an AT-type computer using a DAP 1200 interface card (Microstar, Redmond, WA). The data were analyzed off-line using the Spike/Spidi software package that provides a template-matching procedure for automatic spike discrimination (Forster and Handwerker, 1990).

The magnitude of a chemical response was assessed as the total number of spikes counted in the $5 \mathrm{~min}$ of stimulation. Statistical comparisons were made using the $t$ test for dependent and independent variables. Nonparametric statistical analyses of von Frey threshold changes were made using the Wilcoxon matched pair test. Differences were considered statistically significant at $p<0.05$. The statistical evaluations of changes in heat and mechanical (von Frey) thresholds were complicated by the fact that many fibers were so strongly desensitized after muscarinic agonist administration that heat stimulation (up to $46^{\circ} \mathrm{C}$ ) no longer excited them, and unquantifiable probing with a glass rod was needed to stimulate them mechanically. This resulted in "missing values" that led to underestimation of the effect in the statistical analysis. For illustration, those values are indicated by arrowheads in Figures 3 and 5. In the case of heat responsiveness lost, $46^{\circ} \mathrm{C}$ was entered as default value for heat threshold to enable statistical comparison.

\section{Immunohistochemistry}

Specimens for immunohistochemistry were obtained from five adult rats (Wistar, Harlan Winkelmann, Borchem, Germany) of either sex that were killed by inhalation of chloroform followed by transcardial perfusion with rinsing solution containing polyvinylpyrrolidone and procainamide-HCl (Forssmann et al., 1977) and then with Zamboni's fixative (Zamboni and de Martino, 1967). Specimens of hairy skin from the hindpaws were dissected, washed in $0.1 \mathrm{M}$ phosphate buffer (PB), cryoprotected in $18 \%$ sucrose in $0.1 \mathrm{M} \mathrm{PB}$, and frozen in liquid nitrogen. Sections at a thickness of $10 \mu \mathrm{m}$ were made using a cryostat (Jung Frigocut 1900 E, Leica, Bensheim, Germany). After blocking with PBS containing $10 \%$ normal porcine serum, $0.1 \%$ bovine serum albumin, and $0.5 \%$ Tween 20 , sections were covered overnight with mixtures of primary antisera. Polyclonal M2- or M3-antisera (Biotrend, Köln, Germany) diluted in $\mathrm{PBS} / \mathrm{NaCl}$ 1:1000 were combined with the monoclonal 


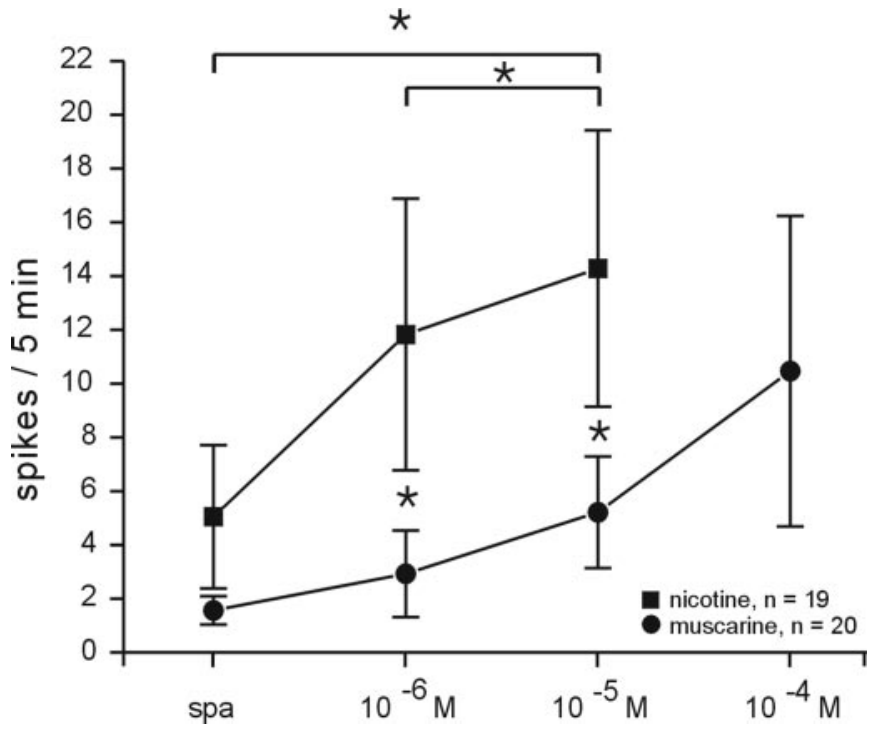

Figure 2. Concentration-response curves for induced C-fiber excitation. Nicotine-induced discharge was of a significantly higher rate than spontaneous activity (spa; recorded during $5 \mathrm{~min}$ before chemical stimulation), and $10^{-5} \mathrm{M}$ nicotine was significantly more effective than $10^{-6} \mathrm{M}\left({ }^{*} p<\right.$ $0.05, t$ test). Both concentrations of nicotine induced significantly more discharge than muscarine $\left({ }^{*} p<0.05, t\right.$ test $)$.

protein gene product (PGP) 9.5 antibody 1:400 (Biotrend). Then, sections were washed in $0.1 \mathrm{M} \mathrm{PB}$ and covered for $1 \mathrm{hr}$ with a mixture of Cy-3-conjugated anti-rabbit IgG (1:3000; Dianova, Hamburg, Germany) and FITC-conjugated anti-mouse IgG (1:400; Cappel, West Chester, PA), washed out, and coverslipped in carbonate-buffered glycerol, $\mathrm{pH}$ 8.6. The slides were evaluated independently by two observers by epifluorescence microscopy (Olympus BX 60 F, Hamburg, Germany) using appropriate filter combinations for Cy3 (excitation filter 525-560 nm, barrier filter $570-650 \mathrm{~nm}$ ) and FITC (excitation filter $460-490 \mathrm{~nm}$, barrier filter $515-550 \mathrm{~nm}$ ). Controls were run by omitting the first antibody.

\section{RESULTS}

We examined 88 mechanosensitive $\mathrm{C}$-fibers from the rat hairy skin, in vitro; $73 \%$ were sensitive to mechanical and heat stimulation (C-MH), $12 \%$ were sensitive to mechanical and cold stimulation (C-MC), and 15\% were high-threshold mechanosensitive (C-HTM) and did not respond to thermal stimulations.

\section{Controls}

For negative control experiments, $13 \mathrm{C}$-MH fibers $(\mathrm{cv}=0.44 \pm$ $0.10 \mathrm{~m} / \mathrm{sec}$ ) were used. We found nearly no spontaneous activity during 5 min of superfusion with SIF (Fig. 2) and no changes of the sensory properties; in fact, mechanical and heat thresholds remained constant after SIF administration (Figs. $3 A, 5 A$ ).

Although the population of $\mathrm{C}$-fibers examined was rather heterogeneous, the differences between the median von Frey and the mean heat responses were not significant between the distinct groups of fibers tested with the various drugs.

\section{Nicotine}

A population of 19 fibers [conduction velocity $(\mathrm{cv})=0.57 \pm 0.22$ $\mathrm{m} / \mathrm{sec}$ ] consisting of nine C-MHs, six C-MCs, and four C-HTMs was tested with nicotine at increasing $10^{-6}$ to $10^{-5} \mathrm{M}$ concentrations (Fig. 1A). Regardless of the fiber type, nicotine induced a significant ( $p<0.05$ compared with control period) and dosedependent excitation with very low discharge rate; 12 of the 19 fibers responded. Seven of the nine C-MH fibers were significantly $(p<0.05)$ and dose-dependently sensitized against heat
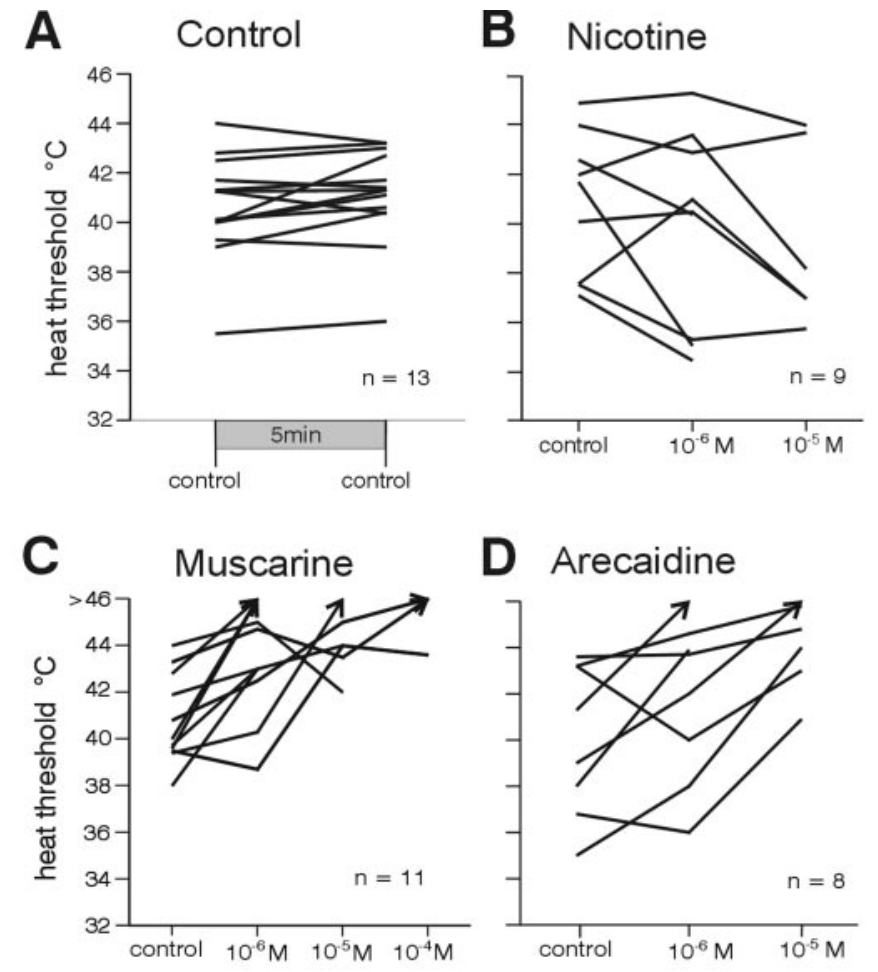

D Arecaidine
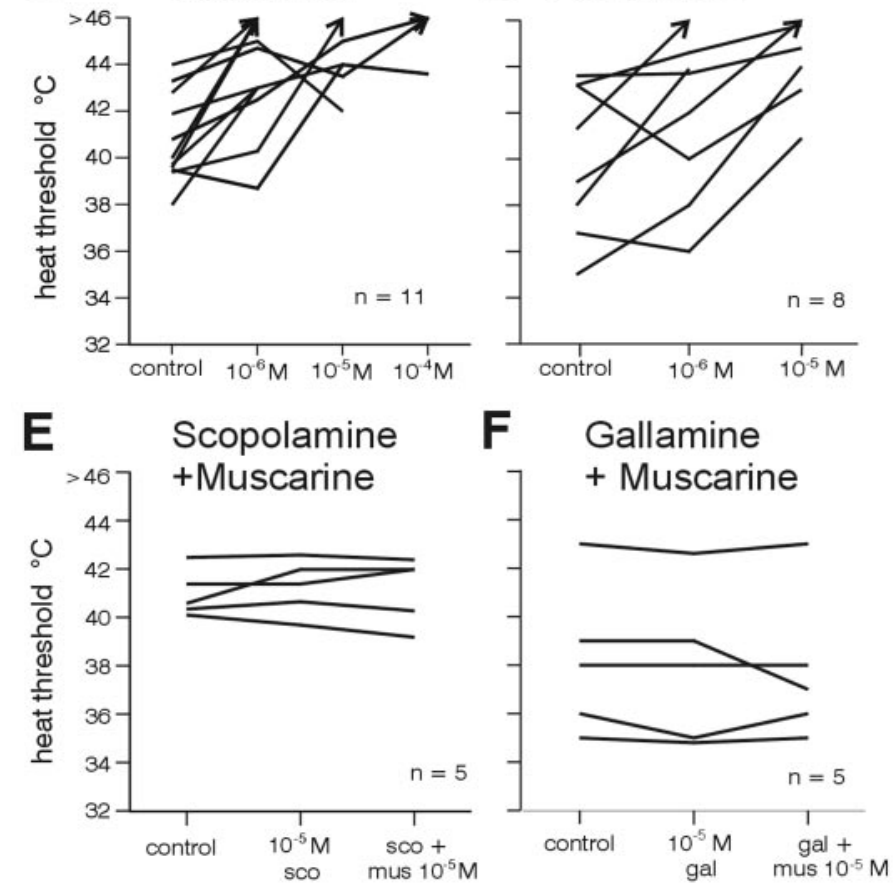

Figure 3. Heat thresholds of C-MH fibers before and after administration of cholinergic agonists and antagonists. Arrowheads in $C$ and $D$ indicate fibers no longer excited up to $46^{\circ} \mathrm{C}$.

stimulation, showing a decrease of the heat threshold (Fig. 3B) and an increase of the heat-induced discharge (from $12 \pm 7$ to $18 \pm 9$ and $23 \pm 16$ spikes after $10^{-6}$ and $10^{-5} \mathrm{M}$ nicotine, respectively) (Fig. 4A). In the majority of the fibers the heat threshold dropped by $>3^{\circ} \mathrm{C}$ (Table 1 ). On the contrary, there was no alteration of the median von Frey threshold (Fig. 5B, Table 2).

\section{Muscarine}

Twenty C-fibers $(\mathrm{cv}=0.59 \pm 0.20 \mathrm{~m} / \mathrm{sec})-11 \mathrm{C}-\mathrm{MH}, 3 \mathrm{C}-\mathrm{MC}$, 6 C-HTM-were tested with muscarine at increasing $10^{-6}$, $10^{-5}$, and $10^{-4} \mathrm{M}$ concentrations (Fig. $1 B$ ); 7 of 20 units showed a slight, apparently dose-dependent but not significant excitation (Fig. 2). Ten of $11 \mathrm{C}-\mathrm{MH}$ units revealed a marked and dosedependent desensitization against heat stimulation (Figs. $3 C, 4 B$, Table 1). Most of the C-MH fibers showed an increase of the heat threshold by $>3^{\circ} \mathrm{C}$ (Fig. $3 C$, Table 1 ) or were no longer excited by heat stimulation up to $46^{\circ} \mathrm{C}$ (Fig. $3 C$, arrows, Table 1). The increase of the heat thresholds was always accompanied by a decrease in the numbers of spikes during heat stimulation (on 

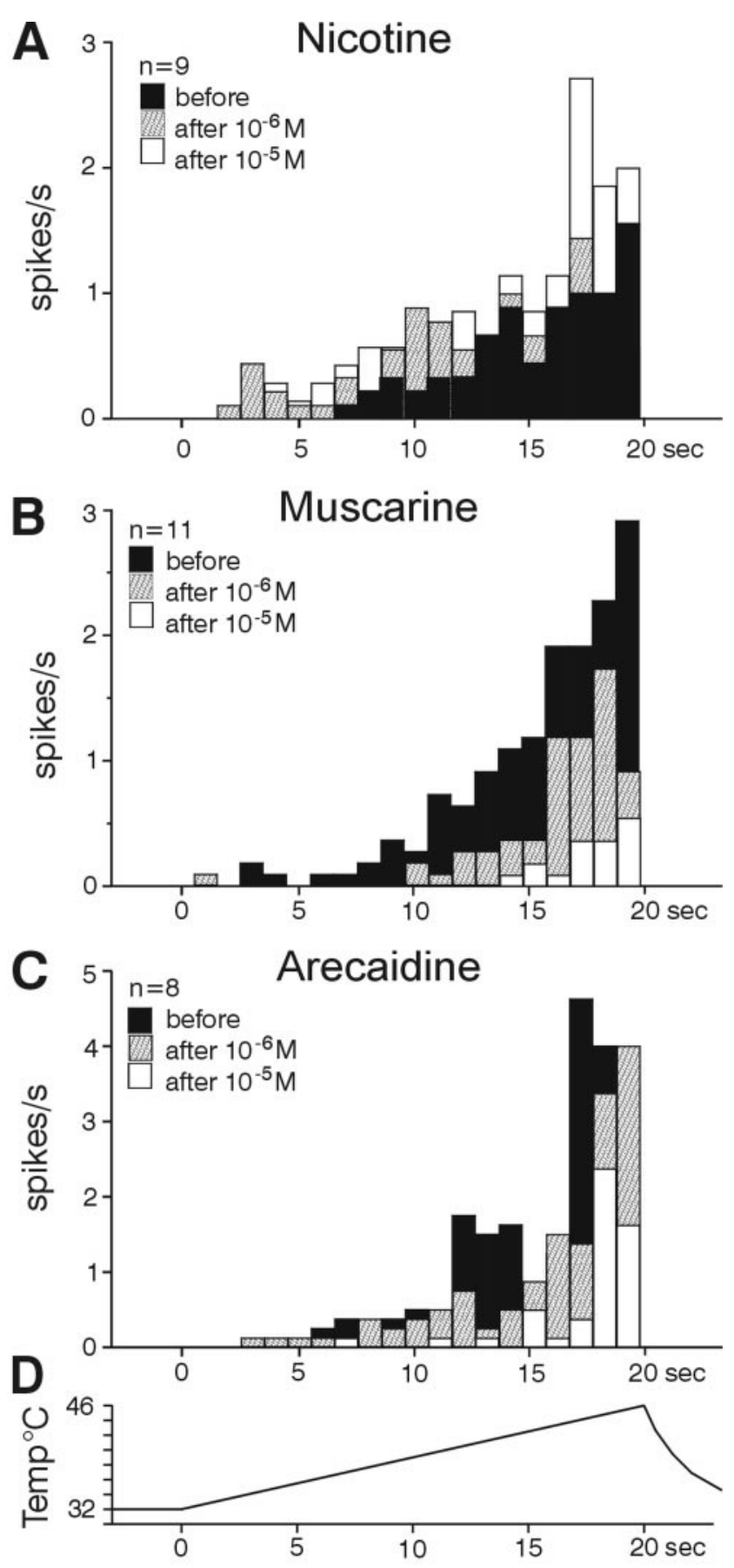

Figure 4. Averaged per stimulus-time histograms of heat responses of $\mathrm{C}$-MH units. Nicotine $(A)$ induced a dose-dependent sensitization, lowering the threshold and increasing the mean response. Muscarine $(B)$ and the M2-agonist arecaidine $(C)$ induced a dose-dependent desensitization with increased threshold and reduced response. $D$ illustrates the heat stimulus. In $A$, a few white columns are masked by gray ones, and in $C$ three black columns vanish behind gray ones, but in all cases the differences were negligible (see Results for statistics).

average from $16 \pm 9$ to $10.2 \pm 8,6.2 \pm 5$, and $2 \pm 1.5$ spikes after increasing muscarine concentrations) as reflected in the averaged heat responses (Fig. 4B). Independent of fiber type, 19 of 20 $\mathrm{C}$-fibers tested were significantly and dose-dependently desensi- tized to mechanical stimulation (Fig. $5 C$ ). In particular, 6 of these 19 fibers responded only to probing of the receptive field with a blunt glass rod applying $\sim 1000 \mathrm{mN}$ of force (Fig. $5 C$, arrows, Table 2); among them, four $\mathrm{C}$ - $\mathrm{MH}$ fibers also no longer responded to heat stimulation.

\section{Muscarinic antagonists}

Seven fibers (one C-MC, one C-HTM, five C-MH; cv $=0.39 \pm$ $0.08 \mathrm{~m} / \mathrm{sec}$ ) were tested with the general muscarinic antagonist scopolamine $\left(10^{-5} \mathrm{M}\right)$ alone and in combination with muscarine at the same concentration. Neither after antagonist alone nor after co-application with muscarine did we find relevant changes of the von Frey or of the heat thresholds (Figs. 3E, 5E). These results were comparable with those of the negative control experiments.

To approach the question of the muscarinic receptor subtype involved in the desensitization, we performed the same type of antagonist experiments using a combination of the noncompetitive M2 antagonist gallamine with the competitive M3 antagonist 4-DAMP (one C-MC, six C-MH; $\mathrm{cv}=0.45 \pm 0.09$ $\mathrm{m} / \mathrm{sec}$ ), obtaining results comparable to those with scopolamine (no change of sensory properties after gallamine alone or in co-application with muscarine; data not shown). Seven (two C-HTM, five C-MH; cv $=0.49 \pm 0.2 \mathrm{~m} / \mathrm{sec}$ ) and 14 $(\mathrm{C}-\mathrm{MH} ; \mathrm{cv}=0.55 \pm 0.16 \mathrm{~m} / \mathrm{sec}$ ) other fibers were tested with either gallamine $\left(10^{-5} \mathrm{M}\right)$ or 4-DAMP $\left(10^{-6} \mathrm{M}\right)$, respectively. As shown in Figures $3 F$ and $5 F$, gallamine was able to prevent muscarine-induced desensitization, because there were no changes of the von Frey and heat thresholds after drug superfusion. However, also on co-application of 4-DAMP with muscarine, only a slight desensitization to heat and no changes of the von Frey thresholds occurred (data not shown); this could be attributable to the fact that the subtype selectivity of 4-DAMP (Caulfield, 1993) is not confined to the M3 receptor $\left(K_{\mathrm{d}}=8.9-9.3\right)$ but overlaps with antagonistic effects on M1 $\left(K_{\mathrm{d}}=8.6-9.2\right), \mathrm{M} 2\left(K_{\mathrm{d}}=7.8-8.4\right), \mathrm{M} 4\left(K_{\mathrm{d}}=8.4-9.4\right)$, and M5 $\left(K_{\mathrm{d}}=8.9-9.0\right)$.

\section{Arecaidine}

To further support M2 involvement in nociceptor desensitization, the M2 agonist arecaidine was tested at $10^{-6}$ and $10^{-5} \mathrm{M}$ concentrations on eight $\mathrm{C}-\mathrm{MH}(\mathrm{cv}=0.43 \pm 0.20)$ fibers. Seven of eight fibers showed a clear dose-dependent desensitization to heat stimulation: in three of them the heat threshold was increased by $>2^{\circ} \mathrm{C}$ and in another two by $>3^{\circ} \mathrm{C}$, and two units no longer responded to heat stimulation up to $46^{\circ} \mathrm{C}$ (Fig. $3 D$, Table 1). Increases in heat threshold were always accompanied by dosedependent decreases in heat-induced discharge (on average from $22 \pm 15$ to $13 \pm 11$ and $5.6 \pm 4$ spikes after $10^{-6}$ and $10^{-5} \mathrm{M}$ arecaidine, respectively) (Fig. $4 D$ ). In all fibers we also found a marked dose-dependent desensitization to mechanical stimulation (Fig. 5D): in three of eight the mechanical threshold was more than doubled, in four of eight it increased $>2.8$-fold, and one fiber responded only to probing of the receptive field with the glass $\operatorname{rod}(\sim 1000 \mathrm{mN})$; the same unit no longer responded to heat stimulation but was still electrically excitable (Fig. 5D, Table 2).

\section{Immunohistochemistry}

M2, but not M3, receptor immunoreactivity (IR) was present in PGP 9.5-positive nerve fibers at the epidermis-dermis border (Fig. 6a,c). Keratinocytes in the basal layer of the epidermis showed a pericellular M3-IR (Fig. $6 c$ ). M2-IR could be detected in the upper epidermal cell layers, whereas the deeper layers showed only a light staining (Fig. $6 a$ ). 
Table 1. Cholinergic effects on heat thresholds

\begin{tabular}{|c|c|c|c|c|c|c|c|}
\hline \multicolumn{3}{|c|}{ Heat threshold } & \multicolumn{2}{|c|}{ Decrease } & \multicolumn{3}{|c|}{ Increase } \\
\hline Treatment & Fibers & No change & $3^{\circ} \mathrm{C}$ & $>3^{\circ} \mathrm{C}$ & $\uparrow 3^{\circ} \mathrm{C}$ & $>3^{\circ} \mathrm{C}$ & $>46^{\circ} \mathrm{C}$ \\
\hline nic & $9 \mathrm{C}-\mathrm{MH}$ & 3 & 1 & 5 & 0 & 0 & 0 \\
\hline mus & $11 \mathrm{C}-\mathrm{MH}$ & 1 & 0 & 0 & 1 & 3 & 6 \\
\hline are & $8 \mathrm{C}-\mathrm{MH}$ & 1 & 0 & 0 & 3 & 2 & 2 \\
\hline
\end{tabular}

nic, Nicotine; mus, muscarine; are, arecaidine.

\section{DISCUSSION}

In the present study we have analyzed the different effects of muscarinic and nicotinic agonists and antagonists on cutaneous nociceptors in the isolated rat skin. Nicotine was able to excite $\mathrm{C}$-nociceptors and to induce a sensitization against heat stimulation in a dose-dependent manner but no alteration in the me-
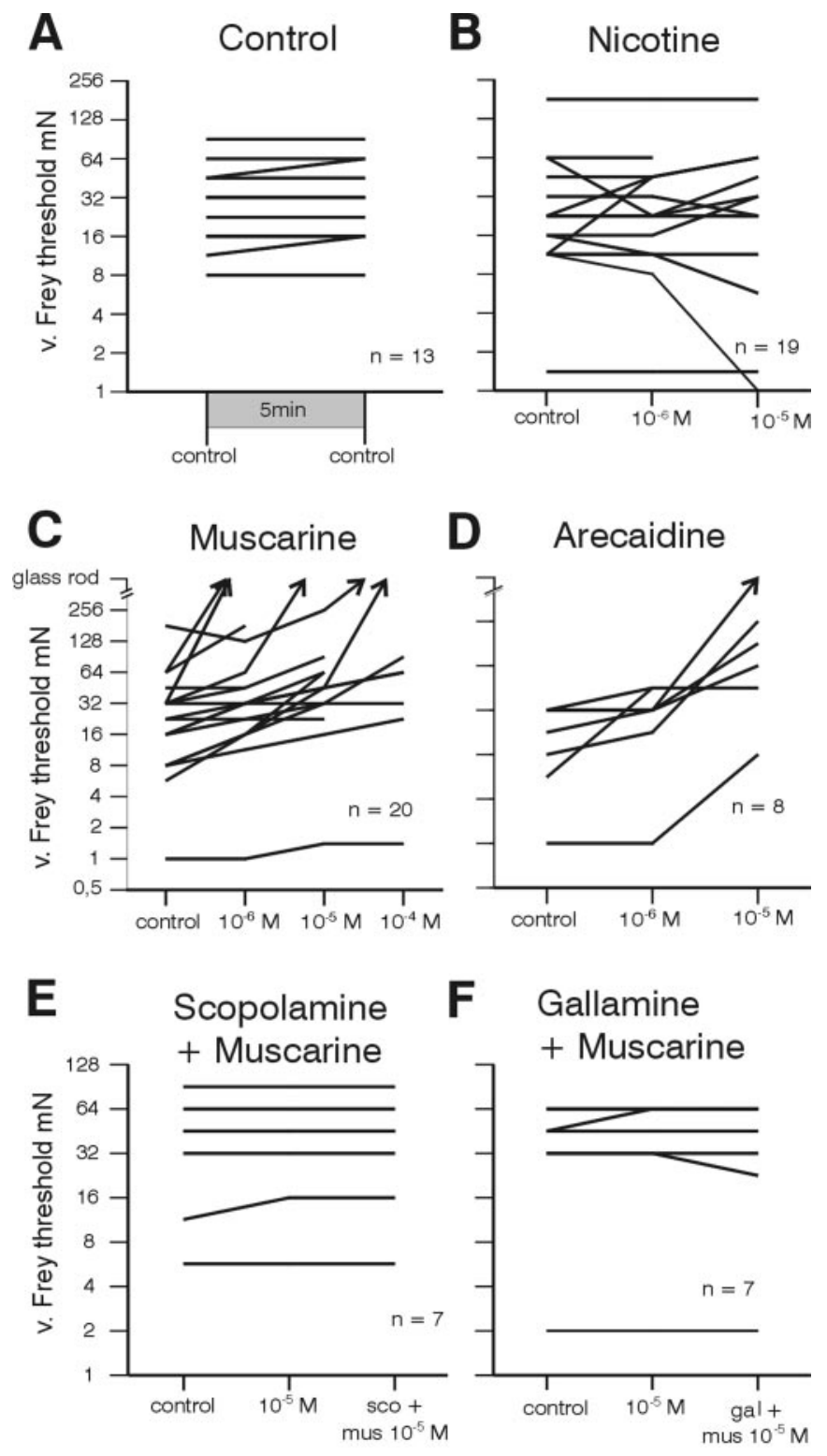

Figure 5. Mechanical thresholds tested with von Frey hairs before and after administration of cholinergic agonists and antagonists. Arrowheads in $C$ and $D$ indicate fibers responding only to a glass rod pressure $(\sim 1000 \mathrm{mN})$. chanical responsiveness. Heat sensitization was found in $77 \%$ of the $\mathrm{C}-\mathrm{MH}$ fibers tested; in $71 \%$ of these, the heat threshold dropped by $>3^{\circ} \mathrm{C}$. On the other hand, muscarine did not produce a significant excitation, but almost all fibers revealed a marked desensitization to mechanical (99\% of the C-fibers tested) and heat $(90 \%$ of the $\mathrm{C}-\mathrm{MH}$ tested) stimulation in a dose-dependent way. Actually 36 and $54 \%$ of the $\mathrm{C}-\mathrm{MH}$ fibers were completely desensitized to mechanical and heat stimulation, respectively. Also $\sim 33 \%$ of the C-HTM showed a complete muscarinic desensitization against mechanical stimuli. The muscarinic effects could be completely prevented by the general muscarinic antagonist scopolamine, by the co-application of the M3 antagonist 4-DAMP together with the M2 antagonist gallamine, and by gallamine alone. These results indicated an M2 or M3 receptor involvement in the desensitization induced by muscarine. For further elucidation we used arecaidine, an M2-specific agonist; here we found the same effects as with muscarine alone. Actually 87 and $100 \%$ of the fibers were desensitized after arecaidine against heat and mechanical stimulation, respectively. Moreover, our immunohistochemical study showed the presence of M2, but not M3, receptors in the unmyelinated nerve fibers at the epidermis-dermis border.

Although acetylcholine has not been recognized as a neurotransmitter in any one of the DRG neuronal populations, it has been demonstrated that sensory neurons are able to synthesize $\mathrm{ACh}$ as well as choline acetyltranferase and acetylcholinesterase (Tata et al., 1994). Moreover, recent experiments demonstrate a widespread expression of the cholinergic system in non-neuronal cells. The synthesizing enzyme choline acetyltranferase, the signaling molecule $\mathrm{ACh}$, and the respective receptors (nicotinic and muscarinic) are expressed in epithelial cells, e.g., in human airways, alimentary tract, and epidermis (Wessler et al., 1998, 1999). Human keratinocytes as well as fibroblasts and glial cells are able to synthesize ACh (Grando et al., 1993; Wessler et al., 1997; Buchli et al., 1999).

Neuronal nicotinic receptors belong to the superfamily of ligandgated ion channels. They exhibit high conductance for $\mathrm{Ca}^{2+}$, which may allow them to take part in synaptic mechanisms in which $\mathrm{Ca}^{2+}$ acts as second messenger to control other ion channels and other intracellular functions (Lindstrom et al., 1996). The presence of nicotinic receptors in sensory neurons is well documented (Boyd et al., 1991), and recent in situ hybridization studies have demonstrated that these receptors belong to the $\alpha 3 \beta 4$ subtype (Zoli et al., 1995; Flores et al., 1996). Our study confirms the presence of functional nAChRs in sensory neurons and demonstrates that they are implicated in $\mathrm{C}$-fiber excitation and heat sensitization. Nicotine-induced excitatory responses in rat sensory neurons (Sucher et al., 1990; Roberts et al., 1995), in rabbit corneal afferent nerves (Tanellian, 1991), and in rat trigeminal ganglion neurons (Liu et al., 1998) have also been demonstrated.

The activation of nicotine receptors in dorsal root ganglion 


\begin{tabular}{|c|c|c|c|c|c|c|c|}
\hline \multicolumn{3}{|c|}{ von Frey threshold } & \multicolumn{2}{|l|}{ Decrease } & \multicolumn{3}{|l|}{ Increase } \\
\hline Treatment & Fibers & $\begin{array}{l}\text { No } \\
\text { change }\end{array}$ & $\downarrow \leq 3$ steps & $\downarrow>3$ steps & $\uparrow \leq 3$ steps & $>3$ steps & $\begin{array}{l}\text { Glass rod } \\
(\sim 1000 \mathrm{mN})\end{array}$ \\
\hline \multirow[t]{3}{*}{ nic } & $9 \mathrm{C}-\mathrm{MH}$ & 3 & 1 & 1 & 1 & 1 & 0 \\
\hline & 4 C-HTM & 3 & 0 & 1 & 0 & 0 & 0 \\
\hline & $6 \mathrm{C}-\mathrm{MC}$ & 3 & 0 & 1 & 2 & 0 & 0 \\
\hline \multirow[t]{3}{*}{ mus } & $11 \mathrm{C}-\mathrm{MH}$ & 0 & 0 & 0 & 3 & 4 & 4 \\
\hline & 6 C-HTM & 1 & & & 2 & 1 & 2 \\
\hline & $3 \mathrm{C}-\mathrm{MC}$ & 0 & 0 & 0 & 1 & 2 & 0 \\
\hline are & $8 \mathrm{C}-\mathrm{MH}$ & 0 & 0 & 0 & 3 & 4 & 1 \\
\hline
\end{tabular}

nic, Nicotine; mus, muscarine; are, arecaidine.

(Zhong and Nurse, 1997) and in PC12 (Harkins and Fox, 1998) cells provides an important $\mathrm{Ca}^{2+}$ entry pathway through both $\mathrm{Ca}^{2+}$-permeable nAChR and voltage-dependent $\mathrm{Ca}^{2+}$ channels. In addition, in C-nociceptors and DRG cells, experimental elevation of intracellular calcium levels induces an increase in the heat responses (Kress and Guenther, 1999). Altogether this evidence can easily explain the sensitization against heat stimulation that we found after nicotine administration.

Five genes that encode mAChR proteins (m1-m5) have been identified (Bonner, 1989; Bonner et al., 1988). They belong to the superfamily of G-protein-coupled receptors and activate different second messenger transduction systems, with $\mathrm{m} 1, \mathrm{~m} 3$, and $\mathrm{m} 5$ (via the $\alpha$ subunits of the $\mathrm{G}_{\mathrm{q} / 11}$ family) acting through the phosphoinositol cascade, whereas $\mathrm{m} 2$ and $\mathrm{m} 4$ (via $\mathrm{G}_{\mathrm{i}}$ and $\mathrm{G}_{0} \alpha$ subunits) mainly lower cAMP levels (Caulfield and Birdsall, 1998). Many studies reported the presence of muscarinic receptors in avian (Bernardini et al., 1998; Tata et al., 2000) and mammalian (Steen and Reeh, 1993; Bauer et al., 1994; Wanke et al., 1994; Bernardini et al., 1999) afferent neurons.

The main finding of the present study was that muscarine treatment of $\mathrm{C}$-units left them with a marked and sustained desensitization to mechanical and heat stimuli. The mechanical desensitization is in agreement with preceding data gained from the same preparation (Steen and Reeh, 1993); it was reported that the ACh analog carbachol excited C-nociceptors and at the same time produced a long-lasting (up to $45 \mathrm{~min}$ ) desensitization to mechanical stimulation. Most of the literature regarding the action of different mediators on nociceptors deals with questions of sensitization (e.g., by inflammatory mediators). So, the literature is poor in respect to endogenous desensitizing effects, but a recent study showed that $\mathrm{GABA}_{\mathrm{B}}$ receptors, which act through G-proteins to regulate potassium and calcium channels, also inhibit mechanosensitivity of primary afferent endings (Page and Blackshaw, 1999). M2 receptors inducing desensitization can be explained by the fact that apart from lowering the intracellular cAMP concentration, they also gate a low-threshold voltageoperated $\mathrm{K}^{+}$channel that builds up a hyperpolarizing force (Pan and Williams, 1994). The activation of these $\mathrm{K}^{+}$channel can also explain the lack of excitation that we found after muscarinic agonist administration. In the skin-nerve preparation application
Figure 6. Immunocytochemical detection of M2 but not M3 ACh receptors in rat cutaneous nerve fibers. Immunoreactivity for M2R, M3R, and PGP 9.5 at the epidermis-dermis border of the rat skin. Some nerve fibers showed immunoreactivity for M2R and PGP 9.5 (arrowheads in $a, b$ ), whereas M3R immunoreactivity could not be observed in PGP 9.5 nerve fibers at the epidermisdermis border (arrows in $c, d$ ). Note the strong M2R-IR of the upper epidermal and the strong M3R-immunoreactivity of the basal epidermal layer. Scale bar, $40 \mu \mathrm{m}$.
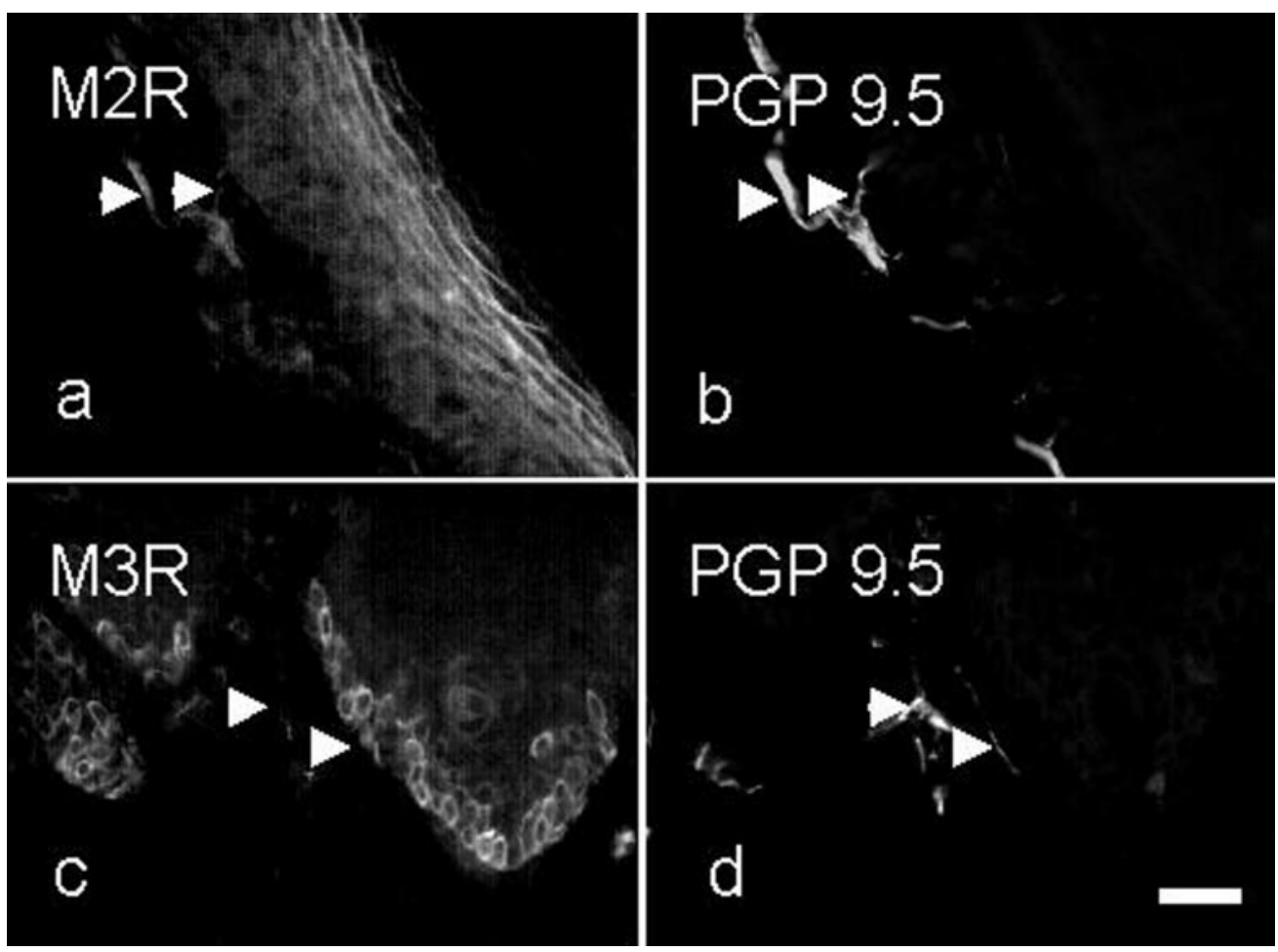
of cAMP, analogs increased the sensitivity for both heat and mechanical stimulation (Kress et al., 1996). So, the opposite, lowering intracellular cAMP (through $\mathrm{G}_{\mathrm{i}}$ and/or $\mathrm{G}_{0}$ ), could contribute to explain the desensitization of nociceptors.

Our results clearly show that the M2 muscarinic subtype is implicated in nociceptor desensitization, and the expression of this subtype in sensory neurons is well documented (Bernardini et al., 1999; Haberberger et al., 1999; Tata et al., 1999). In addition we are showing the presence of M2-IR in nerve fibers in the epidermis of rat hairy skin; this confirms previous immunohistochemical studies in the same preparation (Haberberger and Bodenbenner, 2000).

On the other hand, the involvement of both nicotinic and muscarinic receptors in the modulation of central nociception is well documented. Intrathecal administration of nicotinic agonists has been shown to block heat nociception in the tail-flick assay (Rao et al., 1996; Bannon et al., 1998); among them, epibatidine, is the most powerful. Moreover, the antinociceptive effect of epibatidine was not blocked by the opioid antagonist naloxone, suggesting a therapeutic action different from that of morphine and a potentially novel therapeutic mechanism of providing pain relief (Traynor, 1998). Muscarinic receptors also seem to be implied in central antinociceptive mechanisms (Bartolini et al., 1992; Naguib and Yaksh, 1997). The latest research, using knockout mice, found a crucial role of M2 and M4 receptor subtypes in mediating analgesic effects as assessed in the hot-plate and tailflick tests after oxotremorine administration, which does not exclude the involvement of peripheral nociceptors (Ellis et al., 1999; Gomeza et al., 1999).

In conclusion, the desensitizing muscarine effect was stronger and more general, blunting mechanical and heat sensitivity, than the sensitizing and excitatory nicotinic action. These findings are in full agreement with the previously reported mixed effect of carbachol, weakly exciting and desensitizing nociceptors to mechanical stimulation (Steen and Reeh, 1993). Overall desensitization by endogenous ACh may be the reason why postsurgical patients with joint pain gain benefit from intra-articular instillation of cholinesterase blockers increasing local ACh levels (Yang et al., 1998). In the skin, keratinocytes are a likely source of continuous ACh release (Grando et al., 1993), in the closest possible vicinity to epidermal nerve endings equipped with M2 receptors. Thus, one might speculate that nociceptive mechanosensitivity is normally under permanent inhibitory control that may wane when the keratinocytes are damaged, resulting in disinhibition and mechanical hyperalgesia.

\section{REFERENCES}

Bannon AW, Decker MW, Holladay MW, Curzon P, Donnelly-Roberts D, Puttfarcken PS, Bitner RS, Diaz A, Dickenson AH, Porsolt RD, Williams M, Arneric SP (1998) Broad-sprectrum, non-opioid analgesic activity by selective modulation of neuronal nicotinic acetylcholine receptors Science 279:77-81.

Bartolini A, Ghelardini C, Fantetti L, Malcangio M, Malmberg-Aiello P, Giotti A (1992) Role of muscarinic receptor subtypes in central antinociception. Br J Pharmacol 105:77-82.

Bauer MB, Murphy S, Gebhart GF (1994) Muscarinic cholinergic stimulation of the nitric oxide-cyclic GMP signaling system in cultured rat sensory neurons. Neuroscience 62:351-359.

Bernardini N, De Stefano ME, Tata AM, Biagioni S, Augusti-Tocco G (1998) Neuronal and non-neuronal cell populations of the avian dorsal root ganglia express muscarinic acetylcholine receptors. Int J Dev Neurosci 16:365-377.

Bernardini N, Levey AI, Augusti-Tocco G (1999) Rat dorsal root ganglia express $\mathrm{m} 1-\mathrm{m} 4$ muscarinic receptor proteins. J Peripher Nerv Syst 4:222-232.

Bonner T (1989) The molecular basis of muscarinic acetylcholine receptor diversity. Trends Neurosci 12:148-151.
Bonner T, Young A, Brann M (1988) Cloning and expression of the human and rat $\mathrm{m} 5$ muscarinic acetylcholine receptor genes. Neuron 1:403-410.

Boyd RT, Jacob MH, Mc Earchern AE, Caron S, Berg DK (1991) Nicotinic acetylcholine receptor mRNA in dorsal root ganglion neurons. J Neurobiol 22:1-14.

Bretag A (1969) Synthetic interstitial fluid for isolated mammalian tissue. Life Sci 8:319-329.

Buchli R, Ndoye A, Rodriguez JG, Zia S, Webber RJ, Grando SA (1999) Human skin fibroblasts express $\mathrm{m} 2, \mathrm{~m} 4$, and $\mathrm{m} 5$ subtypes of muscarinic acetylcholine receptors. J Cell Biochem 74:264-277.

Caulfield MP (1993) Muscarinic receptors: characterization, coupling and function. Pharmacol Ther 58:319-379.

Caulfield MP, Birdsall NGM (1998) International union pharmacology. XVII. Classification of muscarinic acetylcholine receptors. Pharmacol Rev 50:279-290.

Ellis JL, Harman D, Gonzales J, Spera ML, Liu R, Shen TY, Wypij M, Zuo F (1999) Development of muscarinic analgesics derived from epibatidine: role of the M4 receptor subtype. J Pharmacol Exp Ther 288:1143-1150

Flores CM, DeCamp RM, Kilo S, Scott WR, Hargreaves KM (1996) Neuronal nicotinic receptor expression in sensory neurons of the rat trigeminal ganglion: demonstration of $\alpha 3 \beta 4$, a novel subtype in the mammalian nervous system. J Neurosci 16:7892-7901.

Forssmann WG, Itoh S, Weihe E, Aoki A, Dym DM, Fawcett DW (1977) An improved perfusion fixation method for the testis. Anat Rec 188:307-318.

Forster C, Handwerker HO (1990) Automatic classification and analysis of microneurographic spike data using a PC/AT. J Neurosci Methods 31:109-118.

Gomeza J, Shannon H, Kostenis E, Felder C, Zhang L, Brodkin J, Grinberg A, Sheng H, Wess J (1999) Pronounced pharmacological deficits in M2 muscarinic acetylcholine receptor knockout mice. Proc Natl Acad Sci USA 96:1692-1697.

Grando SA, Kist DA, Qi M, Dahl MV (1993) Human keratinocytes synthesize, secrete and degrade acetylcholine. J Invest Dermatol 101:32-36.

Haberberger RV, Bodenbenner M (2000) Immunohistochemical localization of muscarinic receptors (M2) in the rat skin. Cell Tissue Res 300:389-396.

Haberberger R, Henrich M, Couraud JY, Kummer W (1999) Muscarinic M2-receptors in rat thoracic dorsal root ganglia. Neurosci Lett 266:177-180.

Harkins AB, Fox AP (1998) Activation of nicotinic acetylcholine receptors augments calcium channel-mediated exocytosis in rat pheochromocytoma (PC12) cells. J Gen Physiol 111:257-269.

Iggo A (1958) The electrophysiological identification of single nerve fibers, with particular reference to the slowest-conducting vagal afferent fibers in the cat. J Physiol (Lond) 142:110-126.

Keele CA, Armstrong D (1964) Substances producing pain and itch. London: Edward Arnold.

Kress M, Guenther S (1999) Role of [ $\left.\mathrm{Ca}^{2+}\right] \mathrm{i}$ in the ATP-induced heat sensitization process of rat nociceptive neurons. J Neurophysiol 81:2612-2619.

Kress M, Rödl J, Reeh PW (1996) Stable analogues of cyclic AMP but not cyclic GMP sensitize unmyelinated primary afferents in rat skin to heat stimulation but not to inflammatory mediatora, in vitro. Neuroscience 74:609-617.

Lindstrom J, Anand R, Gerzanich V, Peng X, Wang F, Wells G (1996) Structure and function of neuronal nicotinic acetylcholine receptors. Prog Brain Res 109:125-137.

Liu L, Chang G-Q, Jiao YQ, Simon SA (1998) Neuronal nicotinic acetylcholine receptors in rat trigeminal ganglia. Brain Res 809:238-245.

Mei L, Roeske WR, Yamamura HI (1989) Molecular pharmacology of muscarinic receptor heterogeneity. Life Sci 45:1831-1851.

Naguib M, Yaksh TL (1997) Characterization of muscarinic receptor subtypes that mediate antinociception in the rat spinal cord. Anesth Analg 85:847-853.

Page AJ, Blackshaw LA (1999) GABAB receptors inhibit mechanosensitivity of primary afferent endings. J Neurosci 19:8597-8602.

Pan ZZ, Williams JT (1994) Muscarine hyperpolarizes a subpopulation of neurons by activating an M2 muscarinic receptor in rat nucleous raphe magnus in vitro. J Neurosci 14:1332-1338.

Pesin SR, Candia O (1982) Acetylcholine concentration and its role in ionic transport by the corneal epithelium. Invest Ophthalmol Vis Sci 22:651-659.

Rao TS, Correa LD, Reih RT, Lloyd GK (1996) Evaluation of antinociceptive effects of neuronal nicotinic acetylcholine receptor (nAChR) ligands in the rat tail-flick assay. Neuropharmacology 35:393-405.

Reeh PW (1986) Sensory receptors in mammalian skin in an in vitro preparation. Neurosci Lett 66:141-146.

Reeh PW (1988) Sensory receptors in mammalian skin-nerve in vitro preparation. In: Progress in brain research. Transduction and cellular 
mechanisms in sensory receptors (Hamann W, Iggo A, eds), pp 271276. Elsevier: Amsterdam.

Roberts RG, Stevenson JE, Westerman RA, Pennefather J (1995) Nicotinic acetylcholine receptors on capsaicin-sensitive nerves. NeuroReport 6:1578-1582.

Rukwied R, Heyer G (1999) Administration of acetylcholine and vasoactive intestinal polypeptide to atopic eczema patients. Exp Dermatol $8: 39-45$.

Steen KH, Reeh PW (1993) Actions of cholinergic agonists and antagonists on sensory nerve endings in rat skin, in vitro. J Neurophysiol 70:397-405.

Sucher NJ, Cheng TPO, Lipton SA (1990) Neural nicotinic acetylcholine responses in sensory neurons from postnatal rat. Brain Res 533:248-254

Tanellian DL (1991) Cholinercic activation of a population of corneal afferent nerves. Exp Brain Res 86:414-420.

Tata AM, Plateroti M, Cibati M, Biagioni S, Augusti-Tocco G (1994) Cholinergic markers are expressed in developing and mature neurons of chick dorsal root ganglia. J Neurosci Res 37:247-255.

Tata AM, Vilaró MT, Agrati C, Biagioni S, Mengod G, Augusti-Tocco G (1999) Expression of muscarinic M2 receptor mRNA in dorsal root ganglia of neonatal rat. Brain Res 824:63-70.

Tata AM, Tripiciano A, Filippini A, Biagioni S, Augusti-Tocco G (2000) Muscarinic receptors modulate intracellular calcium level in chock sensory neurons. Brain Res Mol Brain Res 82:1-10.
Traynor JR (1998) Epibatidine and pain. Br J Anaesth 81:69-76.

Wanke E, Bianchi L, Mantegazza M, Guatteo E, Mancinelli E, Ferroni A (1994) Muscarinic regulation of $\mathrm{Ca}^{2+}$ currents in rat sensory neurons: channel and receptors types, dose-response relationships and cross-talk pathways. Eur J Neurosci 6:381-391.

Wessler I, Reinheimer T, Klapproth H, Schneider FJ, Racke K, Hammer R (1997) Mammalian glial cells in culture synthesize acetylcholine. Naunyn Schmiedeberg's Arch Pharmacol 356:694-697.

Wessler I, Kirkpatrick CJ, Racke K (1998) Non- neuronal acetylcholine, a locally acting molecule, widely distributed in biological systems: expression and function in humans. Pharmacol Ther 77:59-79.

Wessler I, Kirkpatrick CJ, Racke K (1999) The cholinergic "pitfall": acetylcholine, a universal cell molecule in biological systems, including humans. Clin Exp Pharmacol Physiol 26:198-205.

Yang LC, Chen LM, Wang CJ, Buerkle H (1998) Postoperative analgesia by intra-articular neostigmine in patients undergoing knee arthroscopy. Anesthesiology 88:334-339.

Zamboni L, de Martino C (1967) Buffered picric acid formaldehyde: a new rapid fixative for electron microscopy. J Cell Biol 35:148.

Zhong H, Nurse CA (1997) Nicotinic acetylcholine sensitivity of rat petrosal sensory neurons in dissociated cell culture. Brain Res 766:153-161.

Zoli M, Le Noveré N, Hill JA, Changeux JP (1995) Developmental regulation of nicotinic $\mathrm{ACh}$ receptor subunit mRNA in the rat central and peripheral nervous system. J Neurosci 15:1912-1939. 